\title{
Erratum to: Investigation of Mechanical Properties of AA7075 Alloys Aged by Various Heat Treatments
}

\section{T. Sunar ${ }^{a, *}$, T. Tuncay ${ }^{a}$, D. Özyürek ${ }^{a}$, and M. Gürü ${ }^{b}$}

${ }^{a}$ Karabuk University, Technology Faculty, Department of Manufacturing Engineering, Karabuk, 78050 Turkey

${ }^{b}$ Gazi University, Engineering Faculty, Department of Chemical Engineering, Ankara, 06570 Turkey

*e-mail: talhasunar@karabuk.edu.tr

Submitted April 12, 2021; accepted for publication April 12, 2021

DOI: $10.1134 / \mathrm{S} 0031918 X 21130019$

Page 1441, Figure 1 should read as follows (Physics of Metals and Metallography, 2020, Vol. 121, No. 14, pp. 1441):

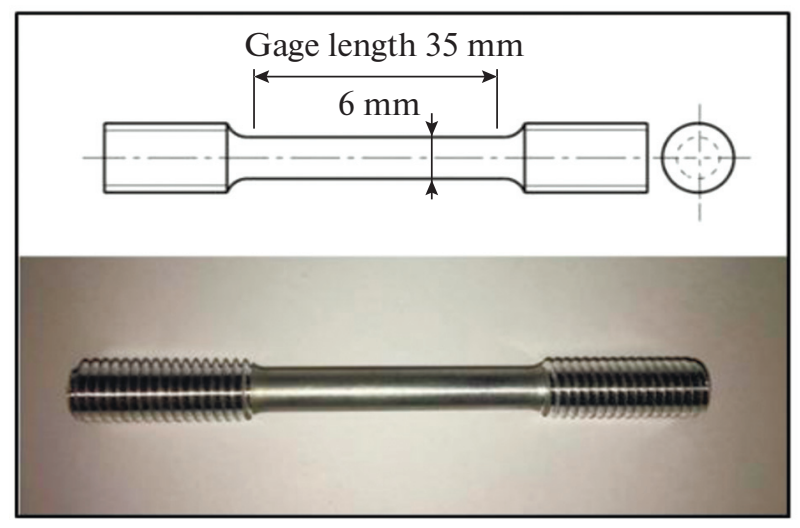

Fig. 1. Tensile test specimen and dimensions.

The original article can be found online at https://doi.org/10.1134/S0031918X20140161 